\title{
Influence of Plasma Sprayed Coatings on Die Life during Hot Forging Process: A State of Art Review
}

\author{
Simran Singh Gill ${ }^{1}$, Kapil Babbar ${ }^{2}$, Subhash Chander $^{3}$ and Vikas Chawla ${ }^{4}$ \\ ${ }^{1 \& 2}$ PG Student, ${ }^{3}$ Assistant Professor, Department of Mechanical Engineering, MIMIT, Malout, Punjab, India \\ ${ }^{4}$ Professor \& Head, Department of Mechanical Engineering, IKGPTU (Main Campus), Kapurthala, Punjab, India \\ E-Mail: simrangill2814@gmail.com, er.kapilbabbar@gmail.com
}

\begin{abstract}
Tooling and die failure is a prime concern for hot forging industry for survival in the competitive globe. Different methods are employed to protect the tools/dies from degradation. Thermal spraying is one of the most effective methods to protect the material from wear, thermal fatigue and plastic deformation due toadverse environments during hot forging process, thus increasing the life of material in use. A coating is a covering process that is applied to the surface of a material which is referred to as the substrate. The coating itself is either completely covered through the whole surface or the particular parts of the substrate. Different coatings are used to achieve the desired properties. In this process, relatively thick metallic, polymer, ceramic and composite coatings is deposited. The optimum coating process is selected on the basis of desired coating properties. Coating material is either in the form of wire, powder, rod, cord or molten-bath form. The procedure may be manual, mechanized or fully automated. This paper attempts to define some of the current important issues and research priorities in the plasma spray field.
\end{abstract}

Keywords: Plasma Spray, Coatings, Die Failure, Microstructure, Scanning Electron Microscope

\section{INTRODUCTION}

Mechanical components have been used in variety of applications to serve under severe conditions of high load, high/low temperature and adverse chemical environment. However, wear is very common problem, which have been faced in almost all industries wherever moving components are involved. As a result, these components are required to be replaced or repaired immediately else it would increase the cost and decrease the service life of the component, thus affecting the efficiency of operation. Surface coatings are widely used which can act as a barrier between the bare metal and the catastrophic environmental conditions thereby enhancing the service life of the component/assembly. Fig. 1 shows the general classification of Surface coating methods. Among the commercially available thermal spray coating techniques,Among the commercially available thermal spray coating techniques, plasma spray is now one of the leading technologies for applying a relatively thick coating (a few hundred of micrometers up to a few millimeters thick) on a substrate to protect its surface or improve its function. It is commonly used in many industrial sectors including aeronautics, industrial gas turbines, automotive, materials mining and processing, biomedical and electronics [1].Two important characteristic parameters for the coating processes are the thickness of the coatings and the deposition temperature. The range of the typical coating thicknesses vary from $0.1 \mu \mathrm{m}$ to $10 \mathrm{~mm}$. The deposition temperature ranges from room temperature to $1000^{\circ} \mathrm{C}[2]$.

The importance of the coating technologies and among them thermal spray is constantly rising, because of coating permits to exploit the cost saving potential by combination of base material that fulfill the structure of demand (Stiffness and strength) with coating material that fulfill the demand on coating surface (Corrosion resistance, wear resistance, electrical isolation \& conductivity, thermal isolation, catalytic function, decorative effect, etc.) E.g. for component that are subject to several stress condition such material can be provided at sufficiently low cost then bulk of material solution that cover both structure and surface demand. Additionally repair of damaged or worn surface of costly components is an important application field for Thermal spray process[3].

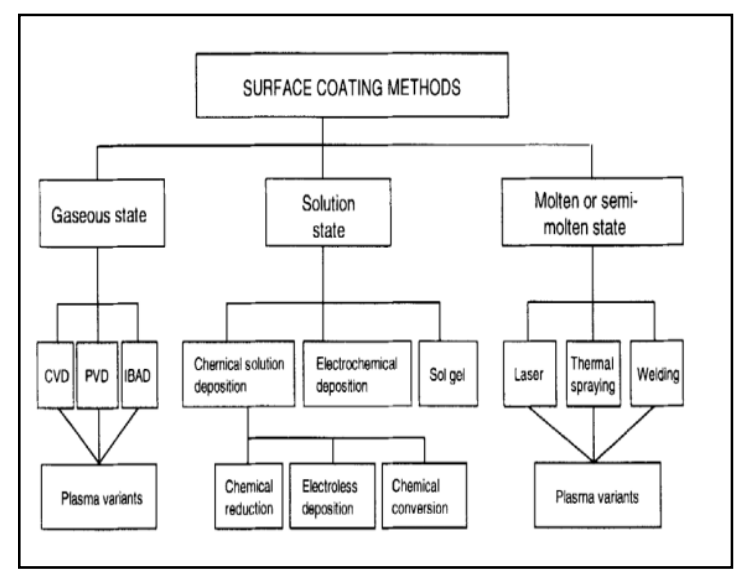

Fig. 1 General Classification of Surface Engineering Techniques

Thermal spraying is a process where the coating materials are melted and with kinetic energy, the particles are impacted onto the substrate surface to be substrate using a stream of gas or compressed air depending on the thermal sparing process coated. The coating material is propelled on the being used, creating a surface structure on a given substrate. The molten or semi-molten materials with kinetic energy impacted on the substrate surface, and rapidly 
solidified, and form splats [20]. The physical properties of thermal spraying coatings, such as porosity, coating density are depend on process parameters such as droplet size distribution, velocity, degree of solidification, substrate material and temperature [21].

Thermal spraying is a technology which improves or restores the surface of a solid material. The process can be used to apply coatings to a wide range of materials and components, to provide resistance to: Wear, erosion, cavitation's, corrosion, abrasion or heat. Thermal spraying is also used to provide electrical conductivity or insulation, lubricity, high or low friction, sacrificial wear, chemical resistance and many other desirable surface properties. Thermal spraying is widely adopted across many industries as a preferred method. It has huge scope to extend the life of new components or through the use of tried and tested techniques, to repair and re-engineer worn or damaged components[5].

Thermal Spray Process can be classified into three categories: Flame; Electrical; Kinetic Fig shows Different process which are been used for Thermal Spray Process.

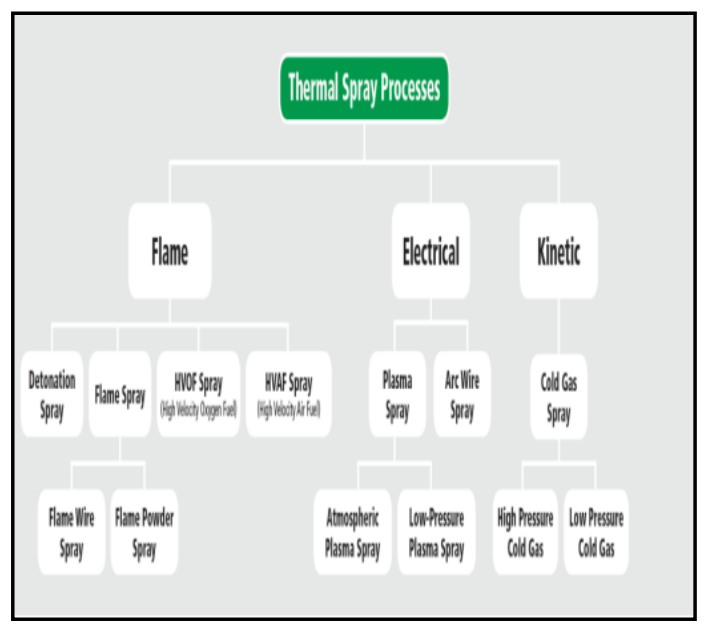

Fig. 2 Thermal spray classification

\section{PLASMA SPRAY THERMAL PROCESS}

The plasma spray process, invented circa 1940, remains one of the most versatile and widely used thermal spray processes. Over the years, process improvements have enhanced the quality and consistency of materials deposited with plasma spray, in conjunction with a continually expanding range of applications for plasma spray coatings

What distinguishes plasma spraying from other coating technologies is its applicability to a large range of materials including refractory materials like ceramics, high deposition rate (up to a few kilograms per hour) and rather simple operation. The main difference between flam and plasma coating is the temperature of powder melting. The temperature of a combustion of flame is limited by enthalpy of chemical reaction that leads to combustion of gases such as acetylene or propane in presence of oxygen while the flame velocity can be boosted in modern equipment (such as HVOF) to values near Mach5, the temperature achievable limited to $3300 \mathrm{~K}$. On other hand plasma jet have temperature of $25000 \mathrm{~K}$ can easily be generated. Thermal spraying of ceramic with high melting points such as alumina $\left(2050^{\circ} \mathrm{C}\right)$ can easily be generated.

It is based on the injection of a powder into a plasma jet formed by electrical to thermal energy released in a plasma torch. The particles are accelerated and heated in the plasma jet and then impact onto the substrate where the sudden deceleration causes a pressure build-up at the particlesurface interface that forces liquid material to flow laterally. The liquid spreads outward from the point of impact, solidifies and forms a lamella; the coating is built by the piling of such lamellae. In air plasma spraying (APS), the size of the injected particles is generally between 10 and $100 \mathrm{~lm}$ and the resulting lamellae have a thickness of a few micrometers and a diameter ranging from a few tens to hundreds of micrometers. Thus, the main reference scale of the features of the coating microstructure (lamellae size, non-melted particles embedded in the coating, voids, cracks, etc.) is the micrometer even if the size of the columns or grains that grow within a lamella during the solidification process can range from a few tens to a few hundreds of nanometers. The minimum coating thickness for the formation of a consistent coating is about $50 \mathrm{~lm}(1 ; 1)$.

\section{A. The Conventional Plasma Torch}

Plasma arc spraying is one of the most sophisticated and versatile thermal spray methods. As indicated in fig. 2, the plasma spray process uses a DC electric arc to generate a stream of high temperature ionized plasma gas, which acts as the spraying heat source[7, 8][9]The plasma gun comprises a copper anode and tungsten cathode, both of which are water cooled.

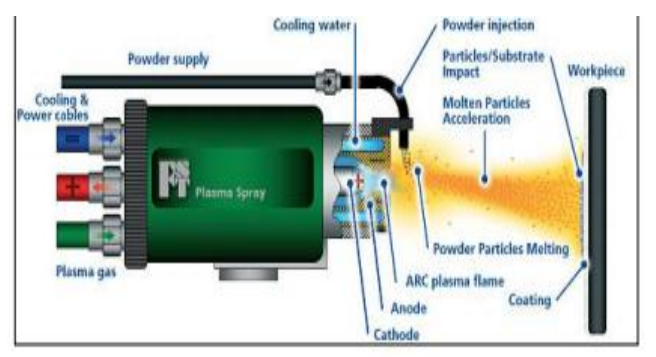

Fig. 3 A systematic diagram Plasma arc spraying

A high frequency arc is ignited between them. Plasma gas (i.e., He, H2, N2 or mixtures) flows around the cathode and through the anode which is shaped as a constricting nozzle and ionized such that a plasma plume several centimeters in length develops. The temperature within the plume can reach as high as $16000^{\circ} \mathrm{K}$. The spray material is injected as a powder outside of the gun nozzle into the plasma plume, where it is melted, and hurled by the gas onto the substrate surface. Provisions for cooling or regulating the spray rate 
may be required to maintain substrate temperatures in the 95 to $205^{\circ} \mathrm{C}$ ( 200 to $400{ }^{\circ} \mathrm{F}$ ) range. Plasma spraying has the advantage that it can spray very high melting point materials such as refractory metals. But main weakness of this technique is the generation of amorphous calcium phosphate and bioactive calcium phosphate phase such as Tetra Calcium Phosphate (TTCP), Tri-Calcium Phosphate (TCP) and meta-stable crystalline products such as oxy hydroxyapatite which may cause mechanical and adhesive instabilities of the coating $[10,11]$.

Plasma spraying is becoming the main process of the thermal spray methods and is commonly used to apply hydroxyapatite to dental implants and orthopedic prostheses. Powder is injected into the plasma flame and accelerated to about $200 \mathrm{~m} / \mathrm{s}$ before impacting the substrate. Mainly due to high impact velocities which supply kinetic energy is spreading the molten droplet and creates lamellar with a large surface area. The large contact area with the substrate associated with the lamellar gives rapid heat transfer which may be sufficient to form the amorphous phase[12].The rate of spray or spray rate is greatly depend on various parameters namely, gun design, plasma gases, powder injection schemes, and materials properties, particularly particle characteristics such as size, distribution, melting point, morphology, and apparent density. [13].

In automotive industry, combustion chamber is coatedwith Zirconia oxide for thermal insulation, and resistance to hot gas oxidation. Atmospheric plasma spraying techniques is use of this type of coating. The crankshaft bearing surface will wear off with time. Dimensional restoration of bearing surface crankshaft can produce considerable saving over the replacement coat. On large scale this process can produce considerable save up to $90 \%$ saving.

In hot forging die require the coating that can with stand the temperature of about $55^{\circ} \mathrm{C}$. Also impact loading that is applied on die is easily be with stand by plasma spray coating.

The conventional plasma, is also commonly known as air or atmospheric plasma spray (APS). In APS, plasma is generated by superheating an inert gas- typically argon or argon-hydrogen mixture by a dc arc. Commercial guns operate at a power range of 20 to $200 \mathrm{KW}$ [10].

TABLE I COMPARISON OF SEVERAL COMMON THERMAL SPRAY PROCESSES

\begin{tabular}{|c|c|c|c|c|c|c|}
\hline Process & $\begin{array}{c}\text { Coating } \\
\text { Material form }\end{array}$ & Heat Source & $\begin{array}{c}\text { Flame Temp } \\
{ }^{\circ} \mathrm{C}\end{array}$ & $\begin{array}{c}\text { Gas recocity } \\
\text { Mts Sec }\end{array}$ & $\begin{array}{c}\text { Porosity } \\
\%\end{array}$ & $\begin{array}{c}\text { Coating } \\
\text { adhesion } \\
\text { MPa }\end{array}$ \\
\hline $\begin{array}{c}\text { Plasma Spray } \\
\text { Wire Arc } \\
\text { Spray } \\
\begin{array}{c}\text { Wire Flame } \\
\text { Spray }\end{array}\end{array}$ & Powder & Plasma Flame & $12000-16000$ & $500-600$ & $2 \cdot 5$ & $40-70$ \\
\hline Wire & $\begin{array}{c}\text { Electric Arc } \\
\text { Oxy-Fuel } \\
\text { combustion }\end{array}$ & $5000-6000$ & 3000 & $<300$ & $5-10$ & $28-41$ \\
\hline HVOF & Powder & $\begin{array}{c}\text { Oxy-gas Fuel } \\
\text { combustion }\end{array}$ & 3200 & 1200 & 1.2 & $>70$ \\
\hline
\end{tabular}

As form the above table we conclude that plasma produces highest temperature/ enthalpy gas jet. Temperature has the capability to melt any engineering material. Quantitative Heat input and High velocity enables wide variation of desired coating properties. Process is capable of high economical deposition rate. ARC HEAT results from electrical I²R amps-ohms[14].

\section{B. Plasma Spray Coating Material Selection}

PLASMA SPRAY is a generic term for a group of processes in which metallic, ceramic, cermets, and some polymeric materials in the form of powder, wire, or rod are fed to a torch or gun with which they are heated to near or somewhat above their melting point. The resulting molten or nearly molten droplets of material are accelerated in a gas stream and projected against the surface to be coated (i.e., the substrate). On impact, the droplets flow into thin lamellar particles adhering to the surface, overlapping and interlocking as they solidify. The total coating thickness is usually generated in multiple passes of the coating device[15][16].

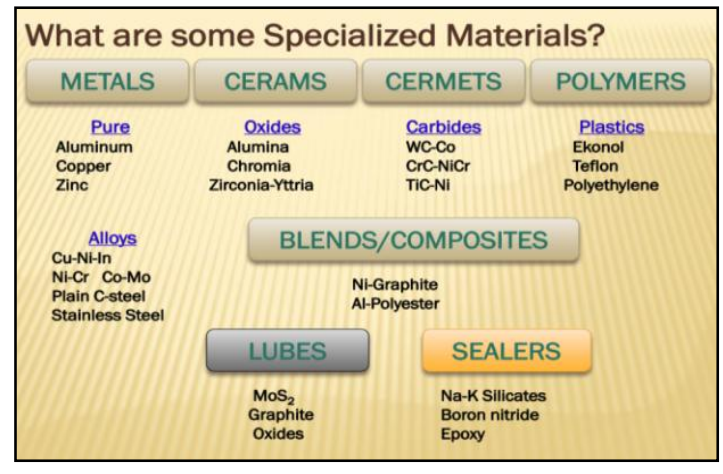

Fig. 4 PLASMA Spray Coating Materials

\section{Coating Requirements for Tool Steel Dies}

The major requirements for a coating to be applied on tool steel dies for resistance against molten $\mathrm{Al}$ are described by [17] as follows

1. Non-wetting with liquid aluminum.

2. Wear and oxidation resistance.

3. Ability to accommodate the thermal residual stresses induced due to heating.

4. Cooling cycles (good thermal shock resistance).

5. Adherence to the die material.

6. Ability to delay the thermal fatigue cracking (heat checking). [19][18]

\section{Materials Processing Technology}

Alumina titania coating produced by plasma spray are being developed for wide variety of application $\mathrm{Al}_{2} \mathrm{O}_{3}(3 \% \mathrm{wt})$ $\mathrm{TiO} 2$ coating produced onto metal substrate. Analysis of coating varied process parameter (current, powder, flow rate and stand of distance). Test shows that increasing current 
flow (550A to $650 \mathrm{~A})$ and powder flow rate from $22.5 \mathrm{~g} / \mathrm{min}$ to $26 \mathrm{gm} / \mathrm{min}$ increase the mechanical properties of coating (adhesion, strength and hardness) and give lowest value of friction coefficient value. Increase of stand of distance from $75 \mathrm{~mm}$ to $90 \mathrm{~mm}$ also increases hardness performance the disadvantage is that increase in stand of distance decreases adhesion strength[22]. Another paper describes the effect of plasma spray distance and A2/ H2 gas mixture ratio on YSZ and CYSZ coating properties are investigated by experiment and characterization study (SEM; Porosity Analysis; Adhesion test and thermal shock test). It was observed that best coated specimen with YSZ produced at $75 \mathrm{~mm}$ spray distance. Also found out that bond strength of coating is between 4 and 10Mpa [23].

The study was undertaken to evaluate plasma spray parameter including spraying current and hydrogen content on the properties of hydroxyapatite (HA) and Fluorapatite(FA) coating. Experiment was performed to find out characterization by SEM \& XRD. FA spray coating potential to show long term use.The following parameter of plasma spraying was considered during experiment[24].

TABLE II SPRAYING PARAMETER OF PLASMA SPRAY

\begin{tabular}{|c|l|c|}
\hline S no & \multicolumn{1}{|c|}{ Spraying Parameter } & Quantity \\
\hline 1 & Primary gas(Ar) Flow rate(1/min) & 41 \\
\hline 2 & Secondary gas (H2) Flow rate(1/min) & $3,6,9$ \\
\hline 3 & Powder carries gas (Ar); Flow rate(1/min) & 5 \\
\hline 4 & Powder feed rate $(\mathrm{g} / \mathrm{min})$ & 25 \\
\hline 5 & Spraying current $(\mathrm{Amp})$ & $460,500,600$ \\
\hline 6 & Stand of distance $(\mathrm{cm})$ & 7.5 \\
\hline 7 & Transverse distance $(\mathrm{mm} / \mathrm{sec})$ & 10 \\
\hline
\end{tabular}

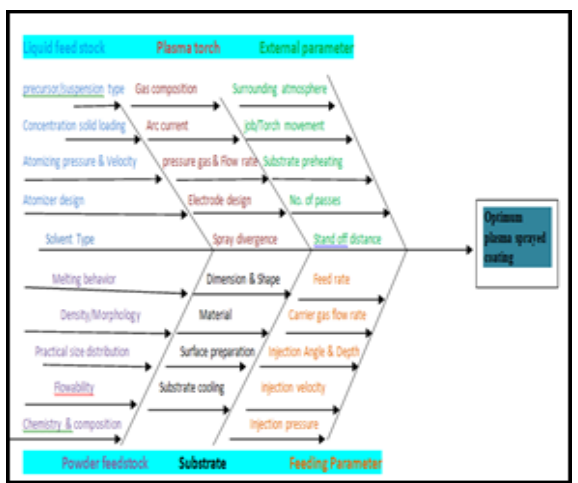

Fig. 5 Influence of the parameter to optimum plasma sprayed coating

Next paper describes the Tio2 coating were prepared on metal substrate by atmospheric plasma spray (APS) using nano - sized feed stock powder. The coating was prepared by varying the plasma spray deposition parameter in order to evaluate mechanical \& microstructure properties of coating. The microstructure and phase composition of coating were characterized using FE- SEM and XRD. The study revealed that by varying the plasma spraying parameters, the coating would experience the change in microstructure strength. In general coating obtained from closer to distance $6.5 \mathrm{~cm}$ led to better mechanical properties then those of coating obtained from $8 \mathrm{~cm}$ spraying distance [24].

\section{E. Deposition or development of coating}

1. Experimental

2. The direct current plasma torch used

To understand what is happening in a hot jet stream, refer to Fig. 4, which shows particle trajectories in a plasma jet. While the figure shows particles entering the gas stream radially, they could just as well be introduced along the centerline of the jet or generated by atomization, as in wire flame spray or electric arc spray. Some particles travel along the jet centerline, others take an intermediate position, and still others ride along the periphery of the jet. Fine particles riding the periphery may, in fact, never enter the main jet, and coarse particles may pass through the jet and take an outside position on the opposite side to their injection point. On impact with the substrate, particles impacting virtually simultaneously make up the spray pattern.

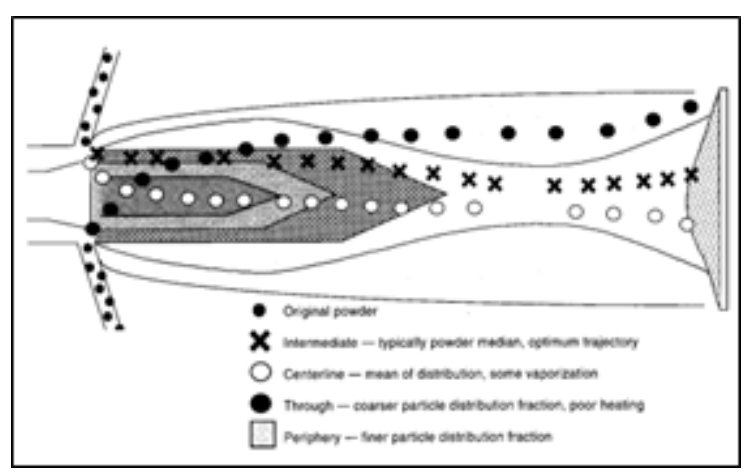

Fig. 6 Particle Trajectories in Typical Plasma Spray Stream

Fig. 6 depicts the spray pattern in cross section. In a planar view, parallel to the substrate, the spray pattern is circular or oval in shape. The deposit at an instant in time is essentially Gaussian in cross section, where, at the center, the highest degree of melting has occurred. Moving radially out from the center, temperatures and velocities are lower, resulting in slightly different microstructures. Each particle will have a unique time/temperature/ velocity profile as it passes through the plume or jet. By maintaining tight control of the feedstock and parameters, the stream can produce a statistically significant number of properly melted and accelerated particles.

The spray-pattern phenomena described in this section and shown in Fig. 4 and 5 apply to all thermal spray processes. Variables common to each process, such as total gas flow, energy levels, particle size distribution, specific gravity, and carrier gas flow, combine to affect time, temperature, and mass. These in turn affect porosity, un-melted particles, and 
oxides quantitatively. The spray pattern varies between processes more as a function of gas stream velocity.

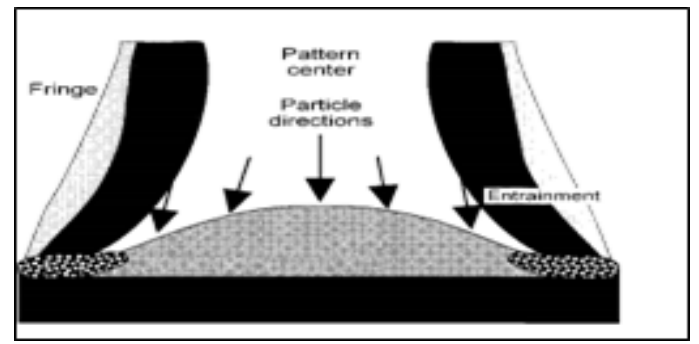

Fig. 7 Deposition and the Effect of Size and Debris on Thickness and Porosity in Cross Section

As the spray stream is manipulated over the part, overlapping occurs. After several passes, a coating results as shown in Fig. 6. A typical coating may include some porosity, un-melted or re-solidified particles, and oxides. Depending on hood and dust collector design, masking and tooling, and airflow around the part, fumes from vaporized feedstock may be trapped in the layers between passes [21, 22, 23, 24].

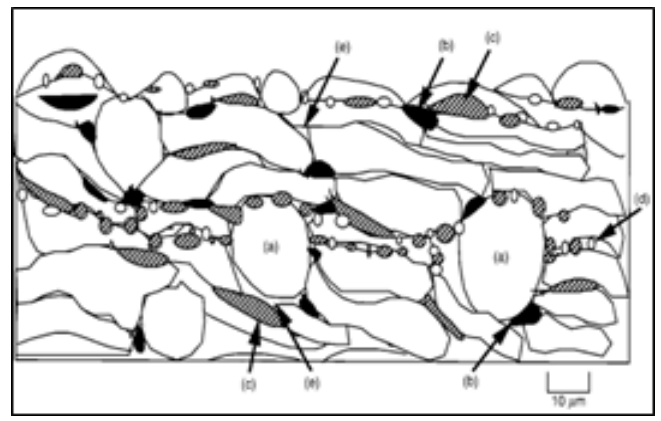

Fig. 8: Typical coating microstructure, containing unmelted particles, oxides, porosity, and debris. (a) Unmelted particles. (b) Oxides. (c) Debris.

(d) Fine particles. (e) Porosity

\section{CHARACTERISTICS OF PLASMA SPRAY COATINGS}

To protect critical parts from damage and increase the functionality of your parts, it is pertinent that they are coated with thermal spray coatings $[22,23]$.

\section{A. Low Porosity}

Generally speaking, the porosity of finished coatings is pretty significant to the coating's protective capability. In most cases, the porosity of finished thermal spray coatings lie somewhere between $3 \%$ and $18 \%$. The percentage also often depends on how the coatings were applied. Next, there are good reasons for a coating to be less porous. For starters, coatings that tends to be less porous have a longer useful service lifespan. If a coating is highly porous, it could corrode at the surface as well as within the pores. See where we are going with this? Of course, you also need to factor in the potential atmospheric conditions that the coatings may be exposed to, before deciding how porous your coatings should be. Porosity can be detrimental in coatings with respect to

1. Corrosion - (sealing of coatings advised).

2. Machined finish.

3. Strength, macro hardness and wear characteristics

\section{B. Oxides}

Most metallic coatings suffer oxidation during normal thermal spraying in air. The products of oxidation are usually included in the coating. Oxides are generally much harder than the parent metal. Coatings of high oxide content are usually harder and more wear resistant. Oxides in coatings can be detrimental towards corrosion, strength and machinability properties.

\section{Uniform Appearance}

Let's pretend that you need Aluminum -based thermal spray coatings. In addition, you also chose the plasma spraying process to apply your coatings. Moving on, you should note that the surface good coatings often have a uniform appearance. Even if defects are present, those defects on the coatings must be limited to small nodules that never exceed $1.1 \mathrm{~mm}$ in diameter. If the height of those nodules (defects) exceeds $0.6 \mathrm{~mm}$, the affected areas have to be fixed promptly before the sealing process takes place.

\section{CONCLUSION}

The following conclusion were concluded

1. With process wide range of material, from metal to ceramic to polymer, and other combination can be deposited.

2. It is possible to deposited mixed ceramic and alloy containing components with widely difference vapor pressure without significant in coating composition.

3. Homogeneous coating with time invariant change in composition.

4. Microstructure with fine, equaled grain but without columnar defect can be deposited.

5. High deposition rate of order $\mathrm{mm} / \mathrm{s}$ can be achieved only modest investment capital equipment.

6. Thermal spray of ceramic with high melting point such as alumina $\left(2050^{\circ} \mathrm{C}\right)$ or zirconia $\left(2680^{\circ} \mathrm{C}\right)$ is domain of plasma due to high temperature process.

7. The process can be carried out in any conceivable environment such air, reduced pressure, inert gas or under water.

8. There are many parameter that influence plasma spray such as Flow rate, spraying current; standoff distance from which it was found by literature survey that bond strength is maximum with substrate at $75 \mathrm{~mm}$ standoff distance which influence the much.

\section{REFERENCES}

[1] "Role of Thermal Spray Coatings on Wear, Erosion and Corrosion Behavior: A Review", Journal of Applied Science and Engineering, Vol. 20, No. 4, pp. 445-452. 
[2] Surface Coating Methods, Tribological series, Vol. 28, pp. 7-32, 1994.

[3] A. Wank, Basic of Thermal spray technology. I process.

[4] Surface Engineering in Material Science I. The Menerals Metals \& Material Society.

[5] Thermal Spray Coating, Metal Hand book, Vol 5. Surface Cleaning, Finishing, Coating Asm Metal Park Ohio, pp. 361-374.

[6] Thermal Spray Tech, pp. 50-58, 1995.

[7] Thermal Spray Coating Technology - A Review, Materials Science and Engineering, pp. 46, 2013.

[8] A Review- Study of Thermal Spray Coatings for Corrosive Wear, International Journal of Advance Research, Ideas and Innovations in Technology.

[9] Very Low Pressure Plasma Spray-A Review of an Emerging Technology in the Thermal Spray Community, Imact Factor, 2011.

[10] E. Pfender, "Plasma Jet Behavior and Modeling Associated with Plasma Spray Process", Thin Solid Films, Vol. 238, pp. 228-241, 1994.

[11] "Some problems Associated with Thermal Sprayed HA Coating:-A Review", International Journal of Surface Engineering \& Material Technology, Vol. 3, June 2013.

[12] "Performance of Plasma Sprayed Hydroxyapatite coating:-Review", Material Fundamentals and Clinical, Vol. 58, 2001, pp. 570-592.

[13] P. Huber, Vakuumplasmaspritzen, Oberflache Surface, Vol.10, 1992, pp. 8.

[14] "Diagnostics of Thermal Spray Plasma Jet", Thermal Spray Technology, Vol. 1, pp. 117-128, 1992.
[15] R.C. Tucker, Themal Spray Coating Surf. Eng. ASM Handbook, 1994.

[16] B. Heimann, Plasma Spray Coating, New York VCH publishers, 1996.

[17] "A Review on Thermal Spray coating", International Journal of Current in Engineering \& Research(IJCTER), Vol. 2, Apiral, pp. 556-563, 2016.

[18] Surface Engineering, ASM Handbook, Vol. 5, pp. 497-509.

[19] P.E. Robert K. Betts, "An Overview of Thermal Spray process", American Galvanizer's Association TECHFORUM, New Orleans, 2016

[20] G.X. Wang, X Jiang, and S Sampathed, S;Seal, N.B. ; Dahotre, J.J; Moore and B. Mishra, (n.d.). The Menerals Metals \& Material Society, 2000.

[21] M. Vardelle, A. Leger, A.C. Fauchais, P. \& D.Gobin, Thermal Spray Tech, pp. 50-58, 1995.

[22] Influence of plasma spray variable parameter on mechanical and wear behavior of plasma sprayed Al2O3 3\% wt. coating Abrasion and Erosion application, Sciverse Science Direct, 2012, pp. 1689-1695.

[23] Effect of air plasma spray parameter on properties of YSZ and CYSZ Thermal Barries coating, Journal of austrialiancermic society, Vol. 52, No. 2, pp. 175-182, 2016.

[24] Effect of plasma spraying parameter on the microstructure and strength of $\mathrm{TiO} 2$ coating, International journal of Mining, Metallurgic and Mechanical Engineering, Vol. 3 No. 4, 2015. 